\title{
Dynamic GnRH and hCG testing: establishment of new diagnostic reference levels
}

\author{
A Kirstine Bang 1,2, Loa Nordkap ${ }^{1,2}$, Kristian Almstrup ${ }^{1,2}$, Lærke Priskorn ${ }^{1,2}$, \\ Jørgen Holm Petersen 1,2,3, Ewa Rajpert-De Meyts 1,2, Anna-Maria Andersson 1,2, \\ Anders Juul ${ }^{1,2}$ and Niels Jørgensen ${ }^{1,2}$
}

'Department of Growth and Reproduction, Rigshospitalet, University of Copenhagen, Copenhagen, Denmark, ${ }^{2}$ International Center for Research and Research Training in Endocrine Disruption of Male Reproduction and Child Health (EDMaRC), Rigshospitalet, Denmark, and ${ }^{3}$ Department of Biostatistics, University of Copenhagen, Copenhagen, Denmark

\author{
Correspondence \\ should be addressed \\ to $\mathrm{N}$ Jørgensen \\ Email \\ niels.joergensen@regionh.dk
}

Abstract

Objective: Gonadotropin-releasing hormone $(\mathrm{GnRH})$ and human chorionic gonadotropin (hCG) stimulation tests may be used to evaluate the pituitary and testicular capacity. Our aim was to evaluate changes in follicular-stimulating hormone (FSH), luteinizing hormone (LH) and testosterone after GnRH and hCG stimulation in healthy men and assess the impact of six single nucleotide polymorphisms on the responses.

Design: GnRH and hCG stimulation tests were performed on 77 healthy men, 18-40 years (reference group) at a specialized andrology referral center at a university hospital. The potential influence of the tests was illustrated by results from 45 patients suspected of disordered hypothalamic-pituitary-gonadal axis.

Methods: Baseline, stimulated, relative and absolute changes in serum FSH and LH were determined by ultrasensitive TRIFMA, and testosterone was determined by LC-MS/MS.

Results: For the reference group, $\mathrm{LH}$ and FSH increased almost $400 \%$ and $40 \%$ during GnRH testing, stimulated levels varied from 4.4 to $58.8 \mathrm{U} / \mathrm{L}$ and 0.2 to $11.8 \mathrm{U} / \mathrm{L}$ and $\mathrm{FSH}$ decreased in nine men. Testosterone increased approximately $110 \%$ (range: $18.7-67.6 \mathrm{nmol} / \mathrm{L}$ ) during hCG testing. None of the polymorphisms had any major impact on the test results. Results from GnRH and hCG tests in patients compared with the reference group showed that the stimulated level and absolute increase in LH showed superior identification of patients compared with the relative increase, and the absolute change in testosterone was superior in identifying men with Leydig cell insufficiency, compared with the relative increase.

Conclusions: We provide novel reference ranges for GnRH and hCG test in healthy men, which allows future diagnostic evaluation of hypothalamic-pituitary-gonadal disorders in men.

\section{Introduction}

The hypothalamic-pituitary-gonadal (HPG) axis regulates the development and maintenance of the male reproductive system. Secretion of the gonadotropins, follicle-stimulating hormone (FSH) and luteinizing hormone (LH), from the pituitary gland is mainly stimulated by the hypothalamic gonadotropin-releasing
C 2017 European Society of Endocrinology Printed in Great Britain hormone $(\mathrm{GnRH})$. Simplified, FSH and LH stimulate spermatogenesis and testosterone (T) production in the testicles respectively.

Decreased testicular function can be due to a primary testicular dysfunction or a dysfunction of the pituitary gland or hypothalamus. Dynamic testing of the HPG

Published by Bioscientifica Ltd. 
axis may facilitate the diagnostic process of testosterone deficiency. The capacity of the pituitary gland for gonadotropin secretion can be assessed by the GnRH test, whereas the capacity of the Leydig cells in the testicles to produce $\mathrm{T}$ can be assessed by the human chorionic gonadotropin (hCG) test $(1,2,3,4,5,6,7,8)$.

The single nucleotide polymorphism (SNP) FSHB $-211 \mathrm{G}>\mathrm{T}$ (rs10835638) in the promoter of the gene coding for the FSH B-subunit leads to a reduced FSH production $(9$, $10,11)$. In addition, both sensitivity and transcriptional activity of the FSH receptor (FSHR) have been linked to the polymorphisms FSHR 2039A $>\mathrm{G}(\mathrm{rs} 6166)$ and the promoter polymorphism FSHR -29G $>$ A (rs1394205) and all three SNPs have been associated to male reproduction $(11,12,13)$. Genetic variants in the LH receptor (LHCGR) might alter the receptor function, and rs2293275 has been associated with spermatogenic damage (14) and rs7371084 and rs4953617 have been associated with testicular germ cell cancer (15). To which degree these polymorphisms affect the GnRH and hCG test responses, have, to our knowledge, not been described. To provide updated reference levels for the GnRH and hCG tests and examine the possible confounding by genetic effect of six gonadotropin-related SNPs, we examined 77 healthy Danish men. The potential usefulness of these reference levels is illustrated by results from 45 patients suspected of disordered HPG axis who had previously been tested.

\section{Subjects and methods}

\section{Healthy participants (reference group)}

Eighty healthy Danish men participating in an ongoing study of testicular function (16) were invited to take part in the hormone tests within a period of three weeks from the primary study. Inclusion criteria were no medical history of chronic diseases, testicular surgery or trauma. During the primary study, the men completed a questionnaire regarding medical history and lifestyle factors, delivered a semen sample and underwent a physical examination (body weight and height, assessment of testicular volume and ultrasound scan of the testicles). All examinations, tests and laboratory assessments were performed at Dept. of Growth and Reproduction, Rigshospitalet, Copenhagen, Denmark between 2012 and 2014. All men received 500 DKK ( 68 Euro) for their participation. Seventy-seven men completed the GnRH and hCG tests. However, five did not show up for the final blood sampling for the hCG tests, leaving results for 72 men on the hCG test.
The study has been approved by the 'Ethical board of the Capital region' (permit number H-2-2012-092).

\section{Hormone testing}

All men had a GnRH test performed directly followed by the initiation of an hCG test. All GnRH tests were started between 08:00 and 12:00 h. Prior to the tests, a baseline blood sample was drawn, which counted as the baseline blood sample for both tests.

\section{GnRH stimulation test}

An intravenous injection of $100 \mu \mathrm{g}$ GnRH (Relefact) was given, and a blood sample was collected after $30 \mathrm{~min}$.

Table 1 Basic description of 77 healthy men.

\begin{tabular}{l} 
Characteristics \\
\hline Basic description, median (min; max) \\
Age (years) \\
Height (cm) \\
Weight (kg) \\
Body mass index $\left(\mathrm{kg} / \mathrm{m}^{2}\right)$ \\
Mean of testis size $(\mathrm{mL})^{\mathrm{a}}$ \\
Total sperm count (million) \\
Alcohol intake (units/week) \\
Smoking, \% ( $n$ ) \\
Daily \\
Occasionally \\
Proven fatherhood \\
Genotypes, \% ( $n$ ) \\
rs10835638 (FSHB $-211 \mathrm{G}>\mathrm{T})$ \\
GG \\
GT \\
TT \\
rs1394205 (FSHR -29G $>$ A) \\
GG \\
GA \\
AA \\
rs6166 (FSHR 2039A $>$ G) \\
AA \\
AG \\
GG \\
rs2293275 (LHCGR S312N) \\
CC \\
CT \\
TT \\
rs7371084 (LHCGR) \\
TT \\
TC \\
CC \\
rs4953617 (LHCGR) \\
TT \\
TC \\
CC \\
\hline
\end{tabular}

\begin{tabular}{c} 
Values \\
\hline \\
$27.0(18 ; 40)$ \\
$183(165 ; 197)$ \\
$77(58 ; 113)$ \\
$22.9(17.3 ; 30.9)$ \\
$14.0(7.7 ; 26.0)$ \\
$221(7 ; 827)$ \\
$7.5(0 ; 60)$ \\
$11.7(9)$ \\
$28.6(22)$ \\
$53.2(41)$ \\
\\
$68.8(53)$ \\
$26.0(20)$ \\
$5.2(4)$ \\
$55.8(43)$ \\
$36.4(28)$ \\
$7.8(6)$ \\
$23.4(18)$ \\
$46.8(36)$ \\
$29.9(23)$ \\
$37.3(28)$ \\
$46.7(35)$ \\
$16.0(12)$ \\
$64.0(48)$ \\
$36.0(27)$ \\
$0(0)$ \\
$85.3(64)$ \\
$14.7(11)$ \\
$0(0)$ \\
\\
\end{tabular}

aMeasured by ultrasound and calculated as mean value of left and right testicle; ${ }^{b} 1$ unit $=12 \mathrm{~g}$ alcohol. Alcohol intake is the sum of intake of beer, wine and strong alcohol the recent week prior to participation in study. 
$h C G$

An injection of 5000 IU hCG (Pregnyl) was given in the gluteal muscle after the final blood sample was taken for the GnRH test. The follow-up blood sample was taken $72 \mathrm{~h}$ later.

All men also had an adrenocorticotropic hormone $(A C T H)$ test performed simultaneously with the GnRH test for another study. Results of this test will not be described here.

\section{Patient group}

We retrospectively identified five patient groups with a total of 45 men from our out-patient clinic. They underwent a GnRH test and/or an hCG test performed the same way as the healthy participants, as part of their clinical work-up of suspected testosterone deficiency between 1996 and 2015. Fourteen patients had been unilaterally orchiectomized due to testicular germ cell cancer and had received irradiation against germ cell neoplasia in situ (GCNIS) in the remaining testis. Eleven were suspected of hypogonadotropic hypogonadism on various backgrounds; pituitary abnormalities (five tumors

Table 2 Serum hormone levels in the reference group of healthy men undergoing $\mathrm{GnRH}$ and hCG test.

\begin{tabular}{|c|c|c|}
\hline & & $\begin{array}{c}\text { Median }(2.5 ; 97.5 \\
\text { percentile) }\end{array}$ \\
\hline \multicolumn{3}{|l|}{ GnRH test $(n=77)$} \\
\hline \multirow[t]{4}{*}{ FSH } & Baseline (IU/L) & $2.6(0.7 ; 7.2)$ \\
\hline & Stimulated (IU/L) & $3.7(0.5 ; 10.5)$ \\
\hline & Absolute increase (IU/L) & $0.9(-1.4 ; 4.7)$ \\
\hline & Relative increase (\%) & $40(-52 ; 128)$ \\
\hline \multirow[t]{4}{*}{ LH } & Baseline (IU/L) & $3.6(1.8 ; 8.4)$ \\
\hline & Stimulated (IU/L) & $17.8(7.4 ; 54.2)$ \\
\hline & Absolute increase (IU/L) & $14.1(3.3 ; 48.6)$ \\
\hline & Relative increase (\%) & $392(69 ; 1068)$ \\
\hline \multicolumn{3}{|l|}{ hCG test $(n=72)$} \\
\hline \multirow[t]{4}{*}{ Testosterone } & Baseline (nmol/L) & $19.1(9.0 ; 34.5)$ \\
\hline & Stimulated (nmol/L) & $40.9(22.8 ; 67.5)$ \\
\hline & $\begin{array}{l}\text { Absolute increase } \\
\text { (nmol/L) }\end{array}$ & $20.7(7.5 ; 46.4)$ \\
\hline & Relative increase (\%) & $111(35 ; 347)$ \\
\hline \multirow[t]{4}{*}{ Estradiol } & Baseline (pmol/L) & $64(17 ; 121)$ \\
\hline & Stimulated (pmol/L) & $166(102 ; 265)$ \\
\hline & $\begin{array}{l}\text { Absolute increase } \\
(\mathrm{pmol} / \mathrm{L})\end{array}$ & $99(17 ; 214)$ \\
\hline & Relative increase (\%) & $150(14 ; 760)$ \\
\hline \multirow[t]{4}{*}{ Free testosterone } & Baseline (pmol/L) & 426 (239; 712) \\
\hline & Stimulated (pmol/L) & $1079(554 ; 1791)$ \\
\hline & $\begin{array}{l}\text { Absolute increase } \\
(\mathrm{pmol} / \mathrm{L})\end{array}$ & $606(203 ; 1444)$ \\
\hline & Relative increase (\%) & $138(39 ; 477)$ \\
\hline
\end{tabular}

and one empty sella), normal pituitary morphology (MRI validated) but absence of puberty (two with Kallmann syndrome and three with isolated hypogonadotropic hypogonadism $(\mathrm{IHH})$ ). Nine were suspected of medically induced testosterone deficiency due to treatment with methadone, morphine, gabapentin or baclofen. Eleven patients were obese men (BMI >30) with a low-normal baseline total testosterone where it was concluded from the clinical work-up that they did not have testosterone deficiency, and therefore, were not offered testosterone treatment.

\section{Hormone and semen analysis}

The blood samples obtained from the healthy participants were allowed to clot, thereafter centrifuged, and serum
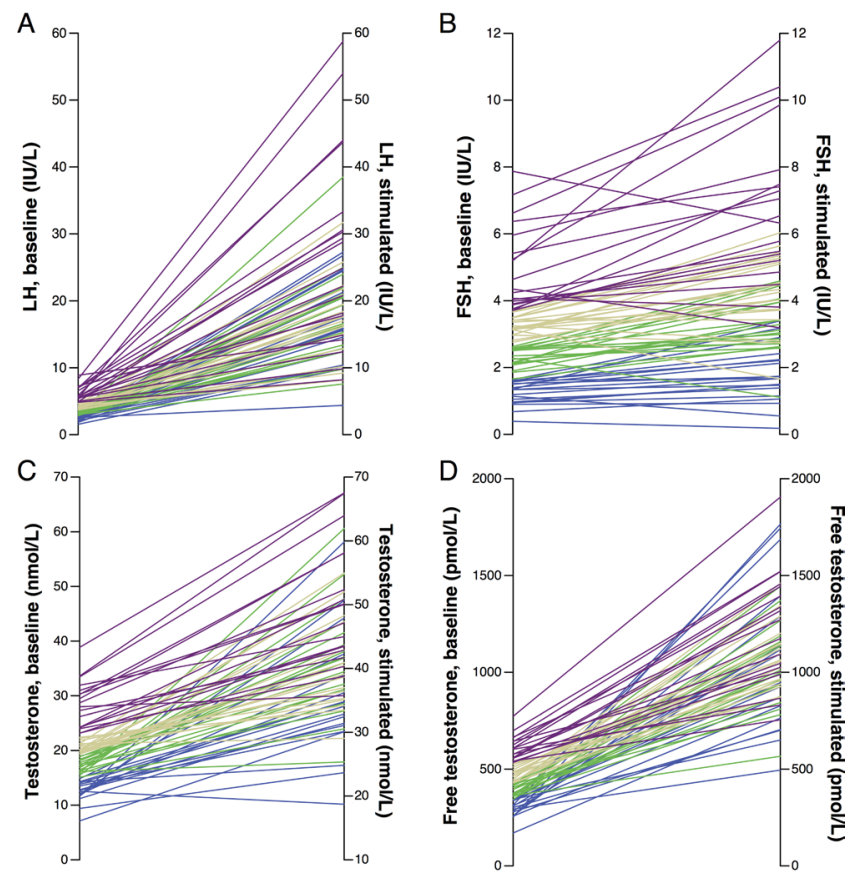

1st quartile 2nd quartile 3 rd quartile 4 th quartile

\section{Figure 1}

(A, B, C and D) Hormone levels at baseline and after GnRH and hCG-test in the reference group of healthy men $(n=77 / 72)$. Results stratified and colored according to baseline quartiles (Blue: 1st quartile, Green: 2nd quartile, Light brown: 3rd quartile, Purple: 4 th quartile). (A) LH levels at baseline and 30 min. after GnRH stimulation. (B) FSH levels at baseline and $30 \mathrm{~min}$. after GnRH stimulation. (C) Testosterone levels at baseline and $72 \mathrm{~h}$ after hCG stimulation. (D) Calculated free testosterone levels at baseline and $72 \mathrm{~h}$ after $\mathrm{hCG}$ stimulation. 
was frozen at $-20^{\circ} \mathrm{C}$ until analysis. Hormone analyses were performed when all subjects had completed their participation. Patients had their hormone analysis done at the time of the visit in the clinic. Serum levels of FSH and LH were determined using a time-resolved immunofluorometric assay (TRIFMA) (Delfia, Wallac, Turku, Finland). Sex hormone-binding globulin (SHBG) was determined by time-resolved chemiluminescent immunoassay (Access, Beckman Coulter). Estradiol levels were determined using radioimmunoassay (Biotech-IGG, Pantex). Inter- and intraassay coefficients of variation (CVs) for measurements of the hormones were FSH (3\% and $2 \%)$, LH ( $2 \%$ and $3 \%$ ), SHBG (5\% and $4 \%$ ) and estradiol (15\% and $8 \%$ ) respectively. Serum testosterone of the healthy volunteers was analyzed by a TurboFlow-LC-MS/MS method (17). The CVs of the low and high level quality control samples were $10 \%$ and $5.7 \%$ respectively in the detection range of 0.071 $36 \mathrm{nmol} / \mathrm{L}$. Limit of quantification (LOQ) was $0.10 \mathrm{nmol} / \mathrm{L}$. Serum testosterone of the patients had been analyzed by radioimmunoassay/RIA (Coat-a-Count, Siemens) with a detection limit of $0.23 \mathrm{nmol} / \mathrm{L}$, intra-assay $\mathrm{CV}$ was $17 \%$ and an inter-assay CV was $13 \%$. For $\mathrm{T}$, the conversion factor to LC-MS/MS from RIA was 1.24 for T (RIA) $>5 \mathrm{nmol} / \mathrm{L}$ and 1.91 for T (RIA) $<5 \mathrm{nmol} / \mathrm{L}$. Patients T-values were corrected according to these factors. Free testosterone was calculated (cFT) according to Vermeulen et al. (18) assuming a fixed albumin value of $43.8 \mathrm{~g} / \mathrm{L}$.

All participants produced semen samples by masturbation, and the samples were assessed as previously described (16). Semen volume was assessed by weighing, assuming a density of $1 \mathrm{~g} / \mathrm{mL}$. For the assessment of the sperm concentration, the samples were diluted in a

Table 3 FSH and LH levels before and after GnRH stimulation stratified according to the 6 different polymorphisms in the reference group of healthy men.

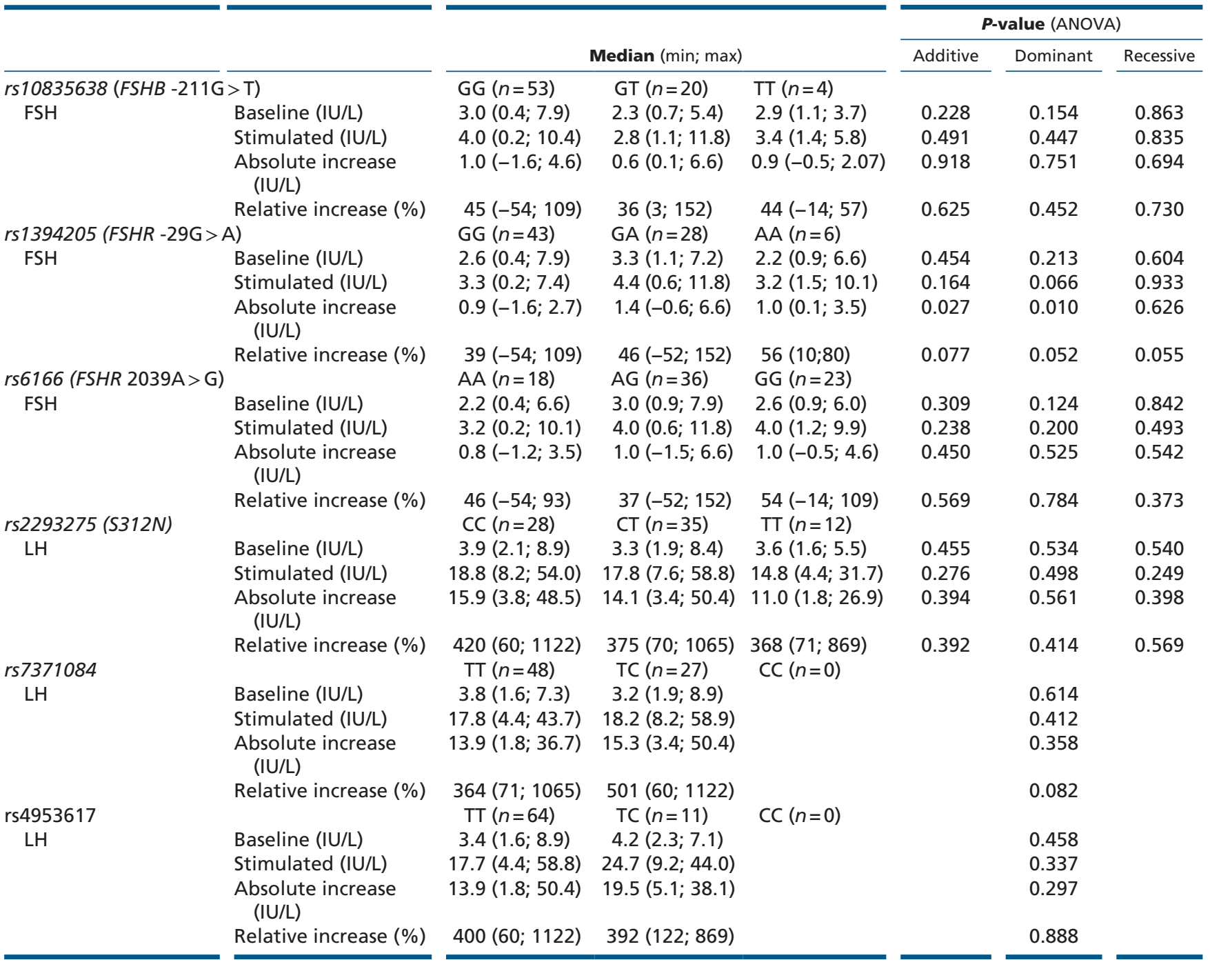


solution of $0.6 \mathrm{~mol} / \mathrm{L} \quad \mathrm{NaHCO}_{3}$ and $0.4 \% \quad(\mathrm{v} / \mathrm{v})$ formaldehyde in distilled water, and subsequently assessed using a Bürker-Türk haemocytometer (Paul Marienfeld $\mathrm{GmbH} \&$ Co. KG, Lauda-Königshofen, Germany). Total sperm count was calculated as semen volume $\times$ sperm concentration.

\section{Genotyping}

Genotyping was performed as described before (19). In short, EDTA-preserved peripheral blood was used for isolation of genomic DNA using the Promega Maxwell 16 DNA purification kits (Promega Biotech $\mathrm{AB}$ ) and quantified on a NanoDrop ND-1000 spectrophotometer (Saveen Werner, Limhamn, Sweden). KASP SNP genotyping assays (LGC Genomics, Hoddesdon, UK) were used to determine the genotypes by competitive PCR. KASP genotyping assays were designed by LGC Genomics toward the following sequences: FSHB -211G $>$ T (rs10835638), TATCAAATTTAATTT[G/T]TACAAAATCATCAT; FSHR -29G>A (rs1394205), TCTCTGCAAATGCAG[A/G]AAGAAA TCAGGTGG; FSHR2039A>G (rs6166), ATGTAAGTGGAA CCA[C/T]TGGTGACTCTGGGA. Genotyping assays for the three LHCGR variants were designed by LGC Genomics toward the following sequences: rs2293275, ACAGTGTTTTRTTR[Y]TCACTKYCCTTACTGT; rs7371084, ACACTGTGGC[Y]TAGRTYKGTTAAGTA; rs4953617, TCCT GGCCAAG[Y]AGATTCTGCCCC.

A master mix containing a low concentration of the ROX fluorophore was used for internal normalization and as negative controls DNA was omitted in the reaction mixture and in all cases showed no amplification. All assays separated samples into clear genotype clusters.

All 77 healthy men were genotyped for the FSHB and the two FSHR variants but only 75 men were genotyped for the $L H C G R$ variants.

Table 4 Testosterone and calculated free testosterone levels before and after hCG stimulation stratified according to the 3 LHCGR polymorphisms in the reference group of healthy men.

\begin{tabular}{|c|c|c|c|c|c|c|c|}
\hline \multirow[b]{3}{*}{ rs2293275 (S312N) } & & \multirow{2}{*}{\multicolumn{3}{|c|}{ Median (min; max) }} & \multicolumn{3}{|c|}{$\boldsymbol{P}$-value (ANOVA) } \\
\hline & & & & & \multirow[t]{2}{*}{ Additive } & \multirow[t]{2}{*}{ Dominant } & \multirow[t]{2}{*}{ Recessive } \\
\hline & & CC $(n=27)$ & $\mathrm{CT}(n=32)$ & $\mathrm{TT}(n=11)$ & & & \\
\hline \multirow[t]{4}{*}{ Testosterone } & Baseline (nmol/L) & $20.3(7.1 ; 33.6)$ & $18.6(11.2 ; 30.3)$ & $15.5(9.4 ; 38.9)$ & 0.488 & 0.458 & 0.722 \\
\hline & Stimulated (nmol/L) & $42.7(29.1 ; 67.5)$ & $40.0(18.7 ; 58.2)$ & $39.0(23.7 ; 67.6)$ & 0.691 & 0.085 & 0.280 \\
\hline & $\begin{array}{l}\text { Absolute increase } \\
(\mathrm{nmol} / \mathrm{L})\end{array}$ & $20.6(7.8 ; 48.2)$ & $20.2(6.2 ; 35.9)$ & $21.1(14.3 ; 39.3)$ & 0.948 & 0.423 & 0.365 \\
\hline & Relative increase (\%) & $102(37 ; 412)$ & $107(28 ; 297)$ & $130(74 ; 253)$ & 0.657 & 0.798 & 0.187 \\
\hline \multirow[t]{4}{*}{ Free testosterone } & Baseline (pmol/L) & $485(171 ; 774)$ & $416(260 ; 663)$ & $395(258 ; 609)$ & 0.338 & 0.435 & 0.445 \\
\hline & Stimulated (pmol/L) & $1135(701 ;$ 1907) & 1018 (495; 1521) & 1057 (705; 1444) & 0.188 & 0.114 & 0.676 \\
\hline & $\begin{array}{l}\text { Absolute increase } \\
\text { (pmol/L) }\end{array}$ & $636(213 ; 1513)$ & $586(202 ; 1136)$ & $639(425 ; 1031)$ & 0.961 & 0.691 & 0.531 \\
\hline & Relative increase (\%) & $133(39 ; 596)$ & $135(38 ; 437)$ & $152(109 ; 397)$ & 0.886 & 0.795 & 0.253 \\
\hline rs7371084 & & $\mathrm{TT}(n=46)$ & $\mathrm{TC}(n=24)$ & $C C(n=0)$ & & & \\
\hline \multirow[t]{4}{*}{ Testosterone } & Baseline (nmol/L) & $18.2(7.1 ; 38.9)$ & $20.0(9.4 ; 33.6)$ & & & 0.488 & \\
\hline & Stimulated (nmol/L) & $39.3(18.7 ; 67.6)$ & $42.8(23.7 ; 61.5)$ & & & 0.285 & \\
\hline & $\begin{array}{l}\text { Absolute increase } \\
(\mathrm{nmol} / \mathrm{L})\end{array}$ & $20.8(6.2 ; 48.2)$ & $20.3(7.8 ; 39.0)$ & & & 0.824 & \\
\hline & Relative increase (\%) & $112(49 ; 412)$ & $108(28 ; 333)$ & & & 0.711 & \\
\hline \multirow[t]{4}{*}{ Free testosterone } & Baseline (pmol/L) & $415(171 ;$ 699) & $472(302 ; 774)$ & & & 0.385 & \\
\hline & Stimulated (pmol/L) & $1026(495 ; 1767)$ & $1138(701 ;$ 1907) & & & 0.270 & \\
\hline & $\begin{array}{l}\text { Absolute increase } \\
\text { (pmol/L) }\end{array}$ & $593(201 ; 1513)$ & $642(213 ; 1351)$ & & & 0.984 & \\
\hline & Relative increase (\%) & $141(56 ; 596)$ & $138(38 ; 401)$ & & & 0.851 & \\
\hline rs4953617 & & $\mathrm{TT}(n=61)$ & $\mathrm{TC}(n=9)$ & $\mathrm{CC}(n=0)$ & & & \\
\hline \multirow[t]{4}{*}{ Testosterone } & Baseline (nmol/L) & $18.9(7.1 ; 38.9)$ & $21.3(12.7 ; 30.3)$ & & & 0.416 & \\
\hline & Stimulated (nmol/L) & $40.9(18.7 ; 67.6)$ & $50.0(31.4 ; 58.1)$ & & & 0.232 & \\
\hline & $\begin{array}{l}\text { Absolute increase } \\
\text { (nmol/L) }\end{array}$ & $20.6(6.2 ; 48.2)$ & $21.0(14.8 ; 39.3)$ & & & 0.282 & \\
\hline & Relative increase (\%) & $111(28 ; 412)$ & $110(62 ; 253)$ & & & 0.666 & \\
\hline \multirow[t]{4}{*}{ Free testosterone } & Baseline (pmol/L) & $423(171 ; 774)$ & $485(260 ; 626)$ & & & 0.986 & \\
\hline & Stimulated (pmol/L) & 1027 (495; 1907) & $1140(872 ; 1457)$ & & & 0.365 & \\
\hline & $\begin{array}{l}\text { Absolute increase } \\
(\mathrm{pmol} / \mathrm{L})\end{array}$ & $602(201 ; 1513)$ & $731(449 ; 1031)$ & & & 0.363 & \\
\hline & Relative increase (\%) & $139(38 ; 596)$ & $137(83 ; 397)$ & & & 0.376 & \\
\hline
\end{tabular}




\section{Statistical analysis}

For descriptive statistics, medians and 2.5-97.5th percentiles or frequencies were calculated for the healthy men used as reference group. Correlations between serum FSH and LH were tested by Spearman's rank-order correlation. Responses to the hormone stimulations were calculated as absolute increase (stimulated-baseline) or relative increase ((stimulated-baseline)/baseline). Paired samples $t$-test was used to compare baseline and stimulated hormonal values. Multivariate linear regression analysis was used to detect the differences in the hormone levels between the different genotype groups (tested as additive, dominant and recessive models). Hormone values were transformed by natural logarithm to obtain variance stability and normalize data in the analysis. Covariates evaluated in the statistical model included factors possibly associated with levels of reproductive hormones (blood sampling hour, age, smoking status, BMI and alcohol consumption) and were included if significant. $P<0.05$ was considered statistically significant. The 2.5 th percentiles of the stimulated levels and increases (absolute and relative) from the healthy reference group were used as cut-off values when comparing with the results from the patients' hormone stimulation tests. SPSS, version 22 for Windows was used for all statistical analyses.

\section{Results}

Table 1 describes the group of healthy men, including genotypes and distribution of alleles. Three men had

Table 5 Testosterone and calculated free testosterone levels before and after hCG stimulation stratified according to the 3 FSH related polymorphisms, in the reference group of healthy men.

\begin{tabular}{|c|c|c|c|c|c|c|c|}
\hline & & & & \multicolumn{3}{|c|}{$\boldsymbol{P}$-value (ANOVA) } \\
\hline & & \multicolumn{3}{|c|}{ Median (min; max) } & Additive & Dominant & Recessive \\
\hline \multicolumn{2}{|c|}{ rs10835638(FSHB $-211 \mathrm{G}>\mathrm{T})$} & GG $(n=50)$ & $\mathrm{GT}(n=18)$ & $\mathrm{TT}(n=4)$ & & & \\
\hline \multirow[t]{4}{*}{ Testosterone } & Baseline (nmol/L) & $19.1(7.1 ; 33.6)$ & $19.4(12.7 ; 38.9)$ & $16.3(12.5 ; 20.2)$ & 0.949 & 0.615 & 0.244 \\
\hline & Stimulated (nmol/L) & $41.3(23.7 ; 67.5)$ & $40.7(25.4 ; 67.6)$ & $34.3(18.7 ; 52.2)$ & 0.162 & 0.499 & 0.026 \\
\hline & $\begin{array}{l}\text { Absolute increase } \\
(\mathrm{nmol} / \mathrm{L})\end{array}$ & $20.6(7.8 ; 48.2)$ & $20.7(9.2 ; 39.3)$ & $18.0(6.2 ; 31.8)$ & 0.308 & 0.611 & 0.113 \\
\hline & Relative increase (\%) & $113(28 ; 412)$ & $103(49 ; 253)$ & $106(49 ; 158)$ & 0.386 & 0.410 & 0.578 \\
\hline \multirow{4}{*}{$\begin{array}{l}\text { Free } \\
\quad \text { testosterone }\end{array}$} & Baseline (pmol/L) & $432(171 ; 774)$ & $430(258 ; 609)$ & $369(294 ; 423)$ & 0.405 & 0.743 & 0.143 \\
\hline & Stimulated (pmol/L) & $1097(701 ; 1907)$ & $992(651 ; 1445)$ & 852 (495; 1189) & 0.023 & 0.099 & 0.013 \\
\hline & $\begin{array}{l}\text { Absolute increase } \\
(\mathrm{pmol} / \mathrm{L})\end{array}$ & $620(212 ; 1513)$ & $582(307 ; 1031)$ & $482(201 ; 766)$ & 0.097 & 0.283 & 0.037 \\
\hline & Relative increase (\%) & $142(38 ; 596)$ & $138(63 ; 397)$ & $125(56 ; 203)$ & 0.267 & 0.363 & 0.316 \\
\hline \multicolumn{2}{|c|}{ rs1394205 (FSHR -29G > A) } & $\mathrm{GG}(n=41)$ & $\mathrm{AG}(n=25)$ & $\mathrm{AA}(n=6)$ & & & \\
\hline \multirow[t]{4}{*}{ Testosterone } & Baseline (nmol/L) & $18.3(9.4 ; 38.9)$ & $19.8(7.1 ; 33.5)$ & $22.5(15.5 ; 31.0)$ & 0.404 & 0.900 & 0.077 \\
\hline & Stimulated (nmol/L) & $40.3(18.7 ; 67.6)$ & $39.0(24.8 ; 64.0)$ & $46.5(40.9 ; 58.2)$ & 0.260 & 0.573 & 0.105 \\
\hline & $\begin{array}{l}\text { Absolute increase } \\
\text { (nmol/L) }\end{array}$ & $20.0(6.2 ; 48.2)$ & $23.0(7.8 ; 35.9)$ & $22.9(16.7 ; 39.3)$ & 0.360 & 0.493 & 0.364 \\
\hline & Relative increase (\%) & $110(28 ; 412)$ & $122(37 ; 322)$ & $106(62 ; 253)$ & 0.899 & 0.602 & 0.519 \\
\hline \multirow{4}{*}{$\begin{array}{l}\text { Free } \\
\text { testosterone }\end{array}$} & Baseline $(\mathrm{pmol} / \mathrm{L})$ & $423(254 ; 773)$ & $429(171 ; 699)$ & $467(260 ; 666)$ & 0.652 & 0.278 & 0.366 \\
\hline & Stimulated (pmol/L) & $1046(567 ; 1907)$ & $1121(495 ; 1523)$ & $1183(938 ; 1319)$ & 0.915 & 0.819 & 0.509 \\
\hline & $\begin{array}{l}\text { Absolute increase } \\
\text { (pmol/L) }\end{array}$ & $602(203 ; 1513)$ & $636(201 ; 1136)$ & $620(485 ; 1031)$ & 0.699 & 0.813 & 0.631 \\
\hline & Relative increase (\%) & $137(38 ; 596)$ & $152(39 ; 437)$ & $146(80 ; 397)$ & 0.660 & 0.456 & 0.755 \\
\hline \multicolumn{2}{|c|}{ rs6166 (FSHR 2039A > G) } & AA $(n=16)$ & AG $(n=34)$ & GG $(n=22)$ & & & \\
\hline \multirow[t]{4}{*}{ Testosterone } & Baseline (nmol/L) & $15.7(7.1 ; 33.6)$ & $19.8(11.2 ; 38.9)$ & $18.6(11.7 ; 33.5)$ & 0.334 & 0.088 & 0.989 \\
\hline & Stimulated (nmol/L) & $41.3(23.7 ; 67.5)$ & $40.6(30.2 ; 67.6)$ & $40.7(18.7 ; 64.0)$ & 0.064 & 0.146 & 0.115 \\
\hline & $\begin{array}{l}\text { Absolute increase } \\
\text { (nmol/L) }\end{array}$ & $23.0(14.3 ; 48.2)$ & $20.4(11.3 ; 34.7)$ & $20.4(6.2 ; 39.0)$ & 0.021 & 0.053 & 0.065 \\
\hline & Relative increase (\%) & $139(53 ; 412)$ & $112(49 ; 214)$ & $105(28 ; 333)$ & 0.007 & 0.003 & 0.111 \\
\hline \multirow{4}{*}{$\begin{array}{l}\text { Free } \\
\quad \text { testosterone }\end{array}$} & Baseline (pmol/L) & $382(171 ; 774)$ & $433(280 ; 666)$ & $391(284 ; 644)$ & 0.450 & 0.138 & 0.884 \\
\hline & Stimulated (pmol/L) & $1160(764 ; 1906)$ & $1055(701 ; 1521)$ & $1075(495 ; 1688)$ & 0.039 & 0.098 & 0.084 \\
\hline & $\begin{array}{l}\text { Absolute increase } \\
(\mathrm{pmol} / \mathrm{L})\end{array}$ & $625(288 ; 1513)$ & $606(336 ; 1027)$ & $614(201 ; 1351)$ & 0.015 & 0.043 & 0.052 \\
\hline & Relative increase (\%) & $157(50 ; 596)$ & $135(63 ; 273)$ & $135(38 ; 401)$ & 0.007 & 0.006 & 0.090 \\
\hline
\end{tabular}


used medicine (antihistamine; $n=2$, dermally applied glucocorticoid; $n=1$ ) at some point during the last 3 months prior to participation. Use of medicine was not significantly associated with any of the hormone levels (data not shown). Among the smokers, 14 men used cannabis or other recreational drugs; for all less than once a month and the use was not associated to any hormone levels (data not shown). Thus, adjusting for men who used the drugs or analyzing data excluding these men did not change the results.

Of the 77 men, 41 men were proven fathers and 36 had unproven fertility status. Total sperm count ranged from 7 to 827 million, with only two men with less than 39 million (7 and 38 million). None of the participants were homozygous minor allele (TT) carriers of LHCGR variants rs7371084 and rs4953617.

\section{GnRH test}

The results of the GnRH and hCG tests in the healthy men are shown in Table 2 and colored according to baseline quartiles in Fig. 1. Tables 3, 4 and 5 show the results stratified according to the polymorphisms. The stimulated gonadotropin levels showed a large variation (Fig. $1 \mathrm{~A}$ and $\mathrm{B}$ ), with stimulated FSH and $\mathrm{LH}$ values in the ranges $0.2-11.8 \mathrm{IU} / \mathrm{L}$ and $4.4-58.8 \mathrm{IU} / \mathrm{L}$ respectively. For FSH, the stimulated level decreased in nine men. The median (min-max) testis size of these men were $14 \mathrm{~mL}(12-22 \mathrm{~mL})$, and total sperm counts 202 million (45-614 million). LH increased in all 77 men. Stimulated values correlated with baseline values for both $\mathrm{FSH}$ $\left(r_{s}: 0.872, P<0.01\right)$ and LH $\left(r_{s}: 0.292, P<0.01\right)$. The relative increase of the LH level (392\%) was much higher than the increase of FSH (40\%), but overall, the serum levels of the two gonadotropins correlated positively (baseline $r_{s}: 0.415$, stimulated $r_{s}: 0.606$, absolute increase $r_{s}: 0.665$ and relative increase $r_{s}: 0.826$, all $P<0.01$ ) (Fig. 2). Age of the men was negatively correlated with the stimulated level $\left(r_{s}:-0.35, P=0.002\right)$ and absolute increase in LH $\left(r_{s}:-0.31, P=0.005\right)$, but not with the change in any other hormones. Smoking status or BMI had no influence on the hormonal increase after GnRH stimulation $(P>0.05)$.

FSH levels were associated to the FSHR $-29 G>A$ genotypes; A-allele carriers had higher absolute increase in FSH: median 0.9IU/L in the GG group, $1.4 \mathrm{IU} / \mathrm{L}$ in the GA group and $1.0 \mathrm{IU} / \mathrm{L}$ in the AA group (additive model, $P=0.027$ and dominant model, $P=0.010$ ), but no difference in baseline levels. No other SNPs were associated with the LH or FSH response (Table 3). The decrease in
FSH levels after GnRH stimulation in the nine men was not associated to any genotype.

\section{hCG test}

Results of the hCG tests are shown in Table 2. Figure 1C and D illustrate the increases in $\mathrm{T}$ and cFT (both $P<0.01)$ stratified into quartiles based on baseline hormone level. The absolute increase in stimulated $\mathrm{T}$ and cFT ranged from 18.7 to $67.6 \mathrm{nmol} / \mathrm{L}$ and 495 to $1907 \mathrm{pmol} / \mathrm{L}$ respectively. The median relative increase in $\mathrm{T}$ was $111 \%$ and in $\mathrm{cFT} 138 \%$. Estradiol also increased $(P<0.01)$, whereas SHBG did not change $(P=0.27)$ (data not shown). Stimulated levels correlated with baseline values for T $(r: 0.475, P<0.01)$ and $c F T$ ( $r: 0.299, P=0.011)$. Stimulated levels of estradiol were positively correlated with the increase in $\mathrm{T}(r: 0.524$, $P<0.01)$ and $\mathrm{CFT}(r: 0.565, P<0.01)$. Age and BMI were negatively associated with baseline levels of T $(P=0.003$ and $P=0.004)$ and cFT $(P=0.012$ and $P=0.001)$, but not associated with stimulated levels $(P>0.05)$. Smoking status was not associated to the $\mathrm{T}$ or cFT response $(P>0.05)$.

None of the 3 LHCGR polymorphisms showed any significant effect on the stimulated $\mathrm{T}$ levels following

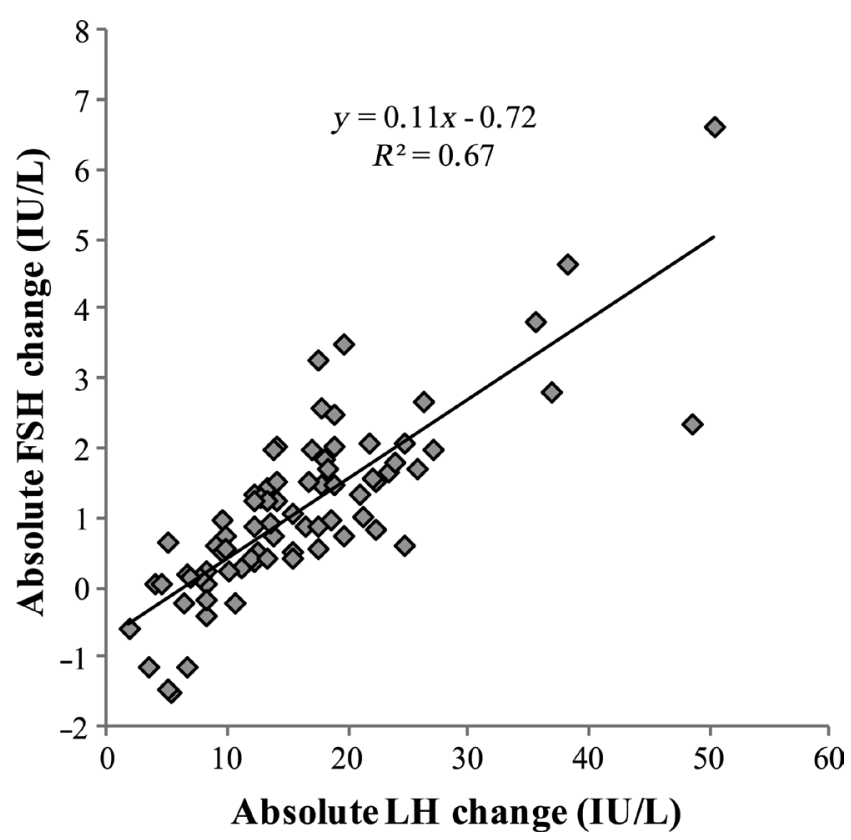

Figure 2

Correlation between the absolute change in $\mathrm{FSH}$ and $\mathrm{LH}$ $30 \mathrm{~min}$ after $\mathrm{GnRH}$ stimulation in the reference group of 77 healthy men. 
an hCG test (Table 4). The FSHB $-211 G>T$ and the FSHR $2039 A>G$ genotypes were associated to the testosterone response after hCG stimulation (Table 5). The T-allele ( FSHB $-211 G>T$ ) carriers had lower stimulated testosterone as well as lower stimulated and absolute cFT increase $(P<0.05)$. For the FSHR 2039A>G genotypes, the G-allele carriers had lower absolute and relative testosterone as well as cFT increase $(P<0.05)$.

\section{Patient groups}

Figure $3 \mathrm{~A}$ and $\mathrm{B}$ show the $\mathrm{LH}$ and $\mathrm{T}$ levels before and after GnRH and hCG stimulation in the healthy men and the 45 patients (Table 6: medians and range). The 2.5th percentiles from the healthy reference group (Table 2) were used as cut-off, and we classified the patients' responses to the two tests on whether or not they reached the 2.5th percentile of the LH levels (stimulated: 7.4 IU/L, absolute increase: $3.3 \mathrm{IU} / \mathrm{L}$ and relative increase: $69 \%$ ) and $\mathrm{T}$ levels (stimulated: $23 \mathrm{nmol} / \mathrm{L}$, absolute increase: $7.5 \mathrm{nmol} / \mathrm{L}$ and relative increase: $35 \%$ ).

\section{GnRH test}

All patients, except one with $\mathrm{IHH}$, had a relative $\mathrm{LH}$ increase above the 2.5th percentile of the healthy participants. Evaluating the absolute increases showed that the two Kallmann patients and two patients with pituitary abnormalities did not reach the cut-off. However, assessing the stimulated level showed that four of the six patients with pituitary abnormalities and one in the group with suspicion of medically induced testosterone deficiency did not reach the cut-off level. All the obese patients and the GCNIS-irradiated patients

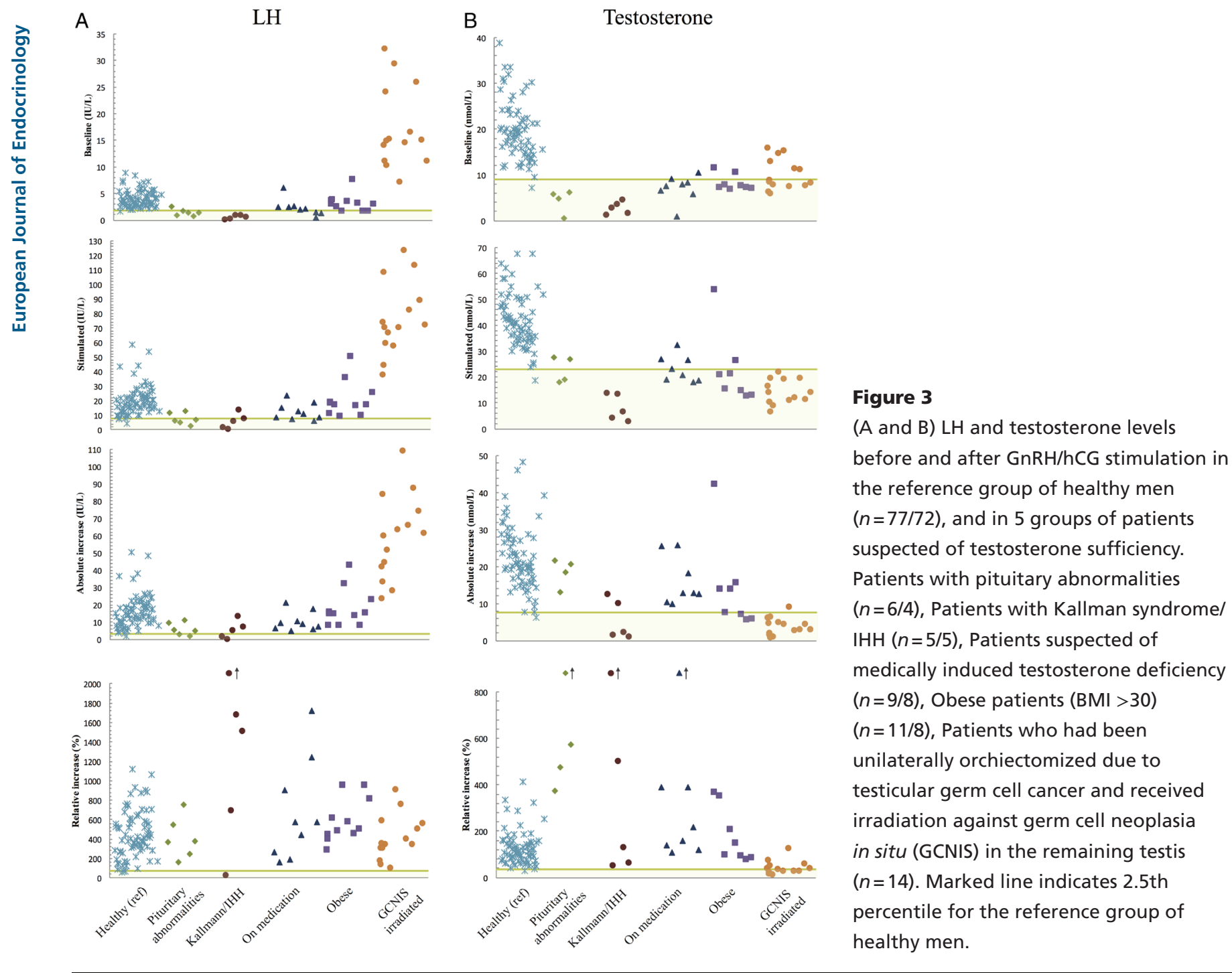

www.eje-online.org 
Table 6 Hormon values at baseline and after hormone stimulation stratified according to 5 groups of patients suspected of testosterone sufficiency.

\begin{tabular}{|c|c|c|c|c|c|c|}
\hline & & \multicolumn{5}{|c|}{ Patient categories } \\
\hline & & $\begin{array}{c}\text { 1. Pituitary } \\
\text { abnormalities }\end{array}$ & $\begin{array}{l}\text { 2. Kallmann } \\
\text { syndrome/lHH }\end{array}$ & 3. On medication & 4. Obese & 5. GCNIS irradiated \\
\hline \multicolumn{2}{|l|}{ GnRH test } & $n=6$ & $n=5$ & $n=9$ & $n=11$ & $n=14$ \\
\hline \multirow[t]{4}{*}{$\mathrm{FSH}$} & Baseline (IU/L) & $2.4(1.3 ; 4.9)$ & $0.8(0.1 ; 1.2)$ & $2.9(1.5 ; 13.9)$ & $3.8(1.2 ; 24.4)$ & $40.6(23.9 ; 59.9)$ \\
\hline & Stimulated (IU/L) & $3.3(1.6 ; 7.2)$ & $2.0(0.4 ; 2.4)$ & $4.0(2.0 ; 16.3)$ & $6.8(1.8 ; 36.1)$ & $61.1(28.9 ; 92.9)$ \\
\hline & $\begin{array}{l}\text { Absolute increase } \\
\text { (IU/L) }\end{array}$ & $1.0(0.4 ; 2.4)$ & $0.9(-0.1 ; 1.4)$ & $1.5(0.3 ; 3.6)$ & $2.2(0.6 ; 11.7)$ & $19.1(-2.0 ; 45.7)$ \\
\hline & Relative increase (\%) & $43(28 ; 57)$ & $101(-9 ; 465)$ & $41(7 ; 143)$ & $48(33 ; 122)$ & $43(-4 ; 100)$ \\
\hline \multirow[t]{4}{*}{ LH } & Baseline (IU/L) & $1.4(0.8 ; 2.52)$ & $0.5(0.0 ; 0.8)$ & $2.0(0.4 ; 6.0)$ & $2.8(1.6 ; 7.5)$ & $14.9(7.0 ; 32.0)$ \\
\hline & Stimulated (IU/L) & $6.5(2.8 ; 12.6)$ & $5.4(0.1 ; 13.7)$ & $11.0(6.4 ; 23.4)$ & $16.9(9.5 ; 50.5)$ & $71.2(37.5 ; 123.0)$ \\
\hline & $\begin{array}{l}\text { Absolute increase } \\
\text { (IU/L) }\end{array}$ & $5.3(2.0 ; 11.1)$ & $4.7(0.0 ; 12.9)$ & $9.0(5.0 ; 21.1)$ & $14.8(7.9 ; 43.1)$ & $60.4(23.5 ; 108.6)$ \\
\hline & Relative increase (\%) & $374(164 ; 757)$ & $1097(20 ; 1679)$ & $576(161 ; 1726)$ & $496(287 ; 950)$ & $345(96 ; 904)$ \\
\hline hCG test & & $n=4$ & $n=5$ & $n=8$ & $n=8$ & $n=14$ \\
\hline \multirow[t]{4}{*}{ Testosterone } & Baseline (nmol/L) & $5.3(0.4 ; 6.2)$ & $2.6(1.2 ; 4.4)$ & $7.8(0.9 ; 10.4)$ & $7.4(6.8 ; 11.5)$ & $8.6(5.8 ; 15.8)$ \\
\hline & Stimulated (nmol/L) & $22.9(17.9 ; 27.5)$ & $6.4(2.5 ; 13.5)$ & $21.9(18.3 ; 32.2)$ & $17.9(12.7 ; 53.7)$ & $12.9(6.5 ; 21.7)$ \\
\hline & $\begin{array}{l}\text { Absolute increase } \\
\text { (nmol/L) }\end{array}$ & $19.6(13.1 ; 21.7)$ & $2.1(1.0 ; 12.4)$ & $12.8(9.8 ; 25.9)$ & $10.7(5.6 ; 42.2)$ & $3.6(0.7 ; 8.9)$ \\
\hline & Relative increase (\%) & $523(374 ; 6855)$ & $128(49 ; 1687)$ & $189(109 ; 4596)$ & $122(78 ; 366)$ & $30(11 ; 122)$ \\
\hline
\end{tabular}

had an LH response higher than the cut-off of both the stimulated and the absolute increase.

\section{hCG test}

Of the 39 patients who had hCG tests performed, only 8 men had a stimulated $\mathrm{T}$ level above the 2.5 th percentile cut-off. For the GCNIS-irradiated patients, all had stimulated levels and absolute increases lower than the cut-off levels in accordance with their clinical symptoms (except one), whereas the relative increase in T levels only detected eight of these men as having an insufficient response. For three of the men with normal pituitary morphology (one with Kallmann syndrome and two with IHH) and four out of the eight obese men, the absolute increase in T was below the cut-off. All men suspected of medically induced testosterone deficiency and those with pituitary abnormalities had an absolute $\mathrm{T}$ increase higher than the cut-off.

\section{Discussion}

In this study, we examined the responses to GnRH and hCG stimulation in healthy Danish men and established normal reference ranges. For both tests, we detected large variations in the stimulated hormone levels, but polymorphisms in genes involved in gonadotropin signaling (FSHB -211G >T, FSHR -29G $>$ A and FSHR 2039A $>$ G and LHCGR (rs2293275, rs7371084 and rs4953617)) did not seem to contribute significantly to this variation.

When comparing the results obtained from the reference group with those of 45 patients suspected of disorders of the HPG axes, it became clear that evaluation of the GnRH test cannot rely on assessing the relative increase in LH as almost all the patients with pituitary failure had a relative increase larger than the 2.5 th percentile of the reference group. Using the absolute increase alone was not always sufficient either. Thus, we recommend that a normal GnRH response should rely on a stimulated $\mathrm{LH}$ level $\geq 7.4 \mathrm{IU} / \mathrm{L}$ combined with an absolute increase of $\geq 3.3 \mathrm{IU} / \mathrm{L}$. Four of the six patients with pituitary abnormalities had an impaired LH response according to the suggested criteria. The two patients with sufficient responses both had pituitary prolactinomas, and their lower baseline LH may be caused by reduced endogenous GnRH secretion rather than a failure of the gonadotrophic cells. Of the five patients with normal pituitary morphology, the two with Kallmann's syndrome responded normally to the GnRH test, and therefore, most likely have a hypothalamic insufficiency rather than a pituitary. In the group with suspicion of medically induced testosterone deficiency, all except one had normal GnRH test responses, in accordance with the inhibitory effect of the drugs primarily on the hypothalamic function (20). 
Evaluating the hCG tests of the patients, only 8 patients actually exceeded the 2.5 th percentile of the stimulated $\mathrm{T}$ levels of the healthy participants. Although the relative increase in $\mathrm{T}$ level could be used to identify men with severe testosterone deficiency, a relative increase can be difficult to use in a clinical setting as very low baseline values can show a markedly relative increase without reaching normal absolute increase or stimulated level. We suggest that a normal adult response to an hCG test should be an absolute increase in $\mathrm{T} \geq 7.5 \mathrm{nmol} / \mathrm{L}$. This also implies that men with secondary testosterone deficiency can increase in $\mathrm{T}$, but not as much as healthy men, and still be considered to have a normal Leydig cell capacity.

The group of obese men may be challenging from a diagnostic point of view. In our study, they all had normal LH responses to GnRH tests indicating that the low baseline LH level detected in this group is not due to a pituitary insufficiency. Among the obese men, four had an abnormal absolute $\mathrm{T}$ change after the hCG stimulation, indicating a reduced Leydig cell capacity, which is in accordance with other studies $(21,22)$. However, this reduced capacity does not exclude that their baseline $\mathrm{T}$ level is sufficient, and in our opinion, it is evident that the clinical decision on whether they need testosterone substitution should not only be based on total $\mathrm{T}$ but also on free $\mathrm{T}$ and symptoms associated with testosterone deficiency. However, if men suspected of testosterone deficiency have large testicles, good semen quality and high serum level of inhibin B, this may additionally be arguments against the presence of testosterone deficiency (23). We found a negative association between BMI and baseline total and free $\mathrm{T}$, but found no association between the increase in $\mathrm{T}$ and BMI in the group of healthy men, probably due to the narrow range in BMI.

Our main objective for this study was to describe the hormone changes for GnRH and hCG test in healthy men and provide novel reference ranges. We included the 45 patients suspected of testosterone deficiency to illustrate the potential use of the cut-off values, not to validate them. It would have been preferable to be able to calculate the diagnostic accuracy for our suggested cut-off values, but our patient group was too small and heterogeneous. In the clinical work-up of patients, their hormone levels are sometimes in a 'gray zone' in contrast to other patients who show clearly abnormal or normal levels. For example, the baseline LH is often very low in patients with hypogonadotropic hypogonadism, and the diagnosis might be obvious and without need for hormone stimulation test, whereas the testosterone levels in obese men are low, and at the same time, they may have low LH. Thus, in such situations, the stimulation tests may help to distinguish between men having a hypogonadotropic hypogonadism and those having an adequately low testosterone level as an adaptation to low SHBG caused by the obesity.

We cannot provide any information of why nine men had a decrease in FSH instead of an increase after the GnRH stimulation. As mentioned in the results, the FSH levels correlated with the LH levels, and the decrease was not associated with their testis size, semen quality or genotypes. However, it is well known that the FSH response is much smaller than the $\mathrm{LH}$ response after GnRH stimulation $(3,8,24)$.

Both tests revealed large variations in the stimulated hormone levels among the healthy men. We anticipated that especially the promoter polymorphism FSHB $-211 \mathrm{G}>\mathrm{T}$ could have been an important modulator of the response to GnRH stimulation due to its strong association to the FSH secretion because other studies have shown that minor allele carriers have lower FSH levels, inhibin B levels and smaller testis volumes (9, $10,11)$. The T-allele carriers of our participants had a tendency for a lower baseline and a lower stimulated FSH level, however, within the range observed for noncarriers. This polymorphism has also been suggested to be adversely associated with androgen production $(9,11)$. In accordance, the T-allele carriers had slightly lower $\mathrm{T}$ and cFT levels after hCG stimulation. The promoter polymorphism $F S H R-29 G>A$ A-allele leads to a reduced FSHR gene expression and is associated to a higher baseline FSH $(13,24,25)$. We also detected a slightly, but significantly, larger increase in FSH level upon GnRH stimulation in the A-allele carriers. For the FSHR 2039A $>$ G polymorphism, which is believed to reduce the FSHR response to FSH (26), our detection of a lower $\mathrm{T}$ response and tendency toward higher levels of stimulated FSH in the G-allele carriers is compatible with previous publications $(27,28)$. Even though we detected significant associations between the FSH-related SNPs and the hormonal responses, the differences were small. None of the tested LHCGR polymorphisms modulated the hCG response. The rs2293275 is located in exon 10 near a glycosylation site, which has been hypothesized to reduce the receptor activity $(14,27,29)$. Although associations between the LHCGR polymorphism and impaired spermatogenesis and under-masculinization have been detected $(14,27,30)$, it has also been shown that deletion of exon 10 only affects the sensitivity to LH and not hCG, which could be an explanation for 
the lack of an association (31). For two of the LHCGR polymorphisms, none were homozygous carriers of the minor allele, and in the FSH-related genotype groups, some of the minor allele groups were small. Men carrying more than one minor allele might be more affected. Testing of a sufficiently large population could probably reveal significant differences in hormone responses between genotypes, and there may be other SNPs that alone or in combination could have a larger effect on the stimulation tests. The investigated SNPs are known to affect steady state levels of hormones, but the effect of genetic variants may be different when the system is stimulated. Based on our results, we recommend that interpretation of both tests can be done without accounting for the six investigated gonadotropin-related polymorphisms.

The strength of our setup was that all 77 participants were healthy without any diseases affecting the testicular function, the first such setup study found in literature. Though previous studies have published results on both GnRH and hCG tests, those studies have included administration of different doses of GnRH/hCG and often with only a few or without healthy controls $(2,5,32,33,34,35,36)$. We used the LC-MS/MS method for testosterone analysis in this group of healthy men. LC-MS/MS-based tests have a higher specificity than immunoassays and are currently believed to be the golden standard in testosterone measurements.

Our study also has some limitations. The hormone levels of the patients in the retrospective part of this study were analyzed by immunoassays as LC-MS/MS was not yet available. Previous studies have shown a good agreement between the LC-MS/MS method and immunoassays, though in the low concentration range, the correlation was lower (17). However, we corrected for the difference between the two methods before comparisons. In the setup of our study, all men had an ACTH test performed simultaneously with the GnRH test for another study. In the routine clinical setting, these tests are often done simultaneously because suspicion of pituitary deficiency should lead to the validation of the other pituitary axes. The knowledge whether the tests influence each other's response is, sparse, but studies have shown that combined pituitary testing does not lead to differences in the hormone responses compared to separate tests $(37,38,39)$. Results from rodents indicate that ACTH can stimulate T production in the neonatal Leydig cells through the ACTH receptor, but apparently without any effect post-pubertally (40).
Also, Leydig cells may have glucocorticoid receptors, and high levels of glucocorticoids have been shown to decrease testosterone production (41).

Even though the age range in our reference group was narrow, we detected a negative association of age on the LH response. This is in accordance with Harman et al. who showed that even though baseline gonadotropins increase slightly with age, there is a lower incremental response to GnRH test (42).

This is the first study to evaluate the dynamic changes in FSH, LH and T after GnRH and hCG stimulation respectively, in a large cohort of healthy men. Hereby, we provide new reference data, which allow future evaluation of men suspected of HPG disorders.

\section{Declaration of interest}

The funders had no role in study design, data collection and analysis, decision to publish or preparation of the manuscript. None of the authors have any competing interests to declare.

\section{Funding}

This study was supported by the Faculty of Health and Medical Sciences, University of Copenhagen, and by the Danish Research Council grant no. DFF - 1331-00044, Nordic Research Committee grant no. R195-A16270, and the A.P. Møller Foundation for the Advancement of Medical Science grant no. 12-164.

\section{Author contribution statement}

Substantial contributions to conception and design: $A \mathrm{~K} \mathrm{~B}, \mathrm{~N} \mathrm{~J}, \mathrm{~N} L$ and A J. Data acquisition: A K B, L N, L P and K A. Data analysis: A K B. Data interpretation: All authors. Drafting the manuscript: A K B and N J. Revising manuscript critically for important intellectual content: All authors. Final approval of the manuscript: All authors.

\section{References}

1 Forest MG. How should we perform the human chorionic gonadotrophin (hCG) stimulation test? International Journal of Andrology 19836 1-4. (doi:10.1111/j.1365-2605.1983.tb00318.x)

2 Harman SM, Tsitouras PD, Costa PT, Loriaux DL \& Sherins RJ. Evaluation of pituitary gonadotropic function in men: value of luteinizing hormone-releasing hormone response versus basal luteinizing hormone level for discrimination of diagnosis. Journal of Clinical Endocrinology and Metabolism 198254 196-200. (doi:10.1210/ jcem-54-1-196)

3 Besser GM, McNeilly AS, Anderson DC, Marshall, JC, Harsoulis P, Hall R, Ormston BJ, Alexander L \& Collins WP. Hormonal responses to synthetic luteinizing hormone and follicle stimulating hormonereleasing hormone in man. British Medical Journal 19723 267-271. (doi:10.1136/bmj.3.5821.267)

4 Cailleux-Bounacer A, Reznik Y, Cauliez B, Menard JF, Duparc C \& Kuhn JM. Evaluation of endocrine testing of Leydig cell function using extractive and recombinant human chorionic gonadotropin and different doses of recombinant human LH in normal men. European Journal of Endocrinology 2008159 171-178. (doi:10.1530/EJE07-0876) 
5 Flanagan JN \& Lehtihet M. The response to gonadotropin-releasing hormone and hCG in men with prior chronic androgen steroid abuse and clinical hypogonadism. Hormone and Metabolic Research 201547 668-673. (doi:10.1055/s-0034-1398492)

6 Isidori AM, Giannetta E \& Lenzi A. Male hypogonadism. Pituitary 200811 171-180. (doi:10.1007/s11102-008-0111-9)

7 Belli S, Santi D, Leoni E, Dall'Olio E, Fanelli F, Mezzullo M, Pelusi C, Roli L, Tagliavini S, Trenti T et al. Human chorionic gonadotropin stimulation gives evidence of differences in testicular steroidogenesis in Klinefelter syndrome, as assessed by liquid chromatographytandem mass spectrometry. European Journal of Endocrinology 2016 174 801-811. (doi:10.1530/EJE-15-1224)

8 Bauman WA, La Fountaine MF, Cirnigliaro CM, Kirshblum SC \& Spungen AM. Provocative stimulation of the hypothalamic-pituitarytesticular axis in men with spinal cord injury. Spinal Cord 201626 1-6. (doi:10.1038/sc.2016.50)

9 Grigorova M, Punab M, Zilaitienẻ B, Erenpreiss J, Ausmees K, Matulevicius V, Tsarev I, Jørgensen N \& Laan M. Genetically determined dosage of follicle-stimulating hormone (FSH) affects male reproductive parameters. Journal of Clinical Endocrinology and Metabolism 201196 1534-1541. (doi:10.1210/jc.2011-0632)

10 Grigorova M, Punab M, Poolamets O, Kelgo P, Ausmees K, Korrovits P, Vihljajev V \& Laan M. Increased prevalance of the $-211 \mathrm{~T}$ allele of follicle stimulating hormone (FSH) B subunit promoter polymorphism and lower serum FSH in infertile men. Journal of Clinical Endocrinology and Metabolism 201095 100-108. (doi:10.1210/jc.2009-1010)

11 Tüttelmann F, Laan M, Grigorova M, Punab M, Sõber S \& Gromoll J. Combined effects of the variants FSHB $-211 \mathrm{G}>\mathrm{T}$ and FSHR 2039A $>\mathrm{G}$ on male reproductive parameters. Journal of Clinical Endocrinology and Metabolism 201297 3639-3647. (doi:10.1210/jc.2012-1761)

12 Lindgren I, Giwercman A, Axelsson J \& Lundberg Giwercman Y. Association between follicle-stimulating hormone receptor polymorphisms and reproductive parameters in young men from the general population. Pharmacogenetics and Genomics 201222 667-672. (doi:10.1097/FPC.0b013e3283566c42)

13 Wunsch A, Ahda Y, Banaz-Yaşar F, Sonntag B, Nieschlag E, Simoni M \& Gromoll J. Single-nucleotide polymorphisms in the promoter region influence the expression of the human folliclestimulating hormone receptor. Fertility and Sterility 200584 446-453. (doi:10.1016/j.fertnstert.2005.02.031)

14 Simoni M, Tüttelmann F, Michel C, Böckenfeld Y, Nieschlag E \& Gromoll J. Polymorphisms of the luteinizing hormone/chorionic gonadotropin receptor gene: association with maldescended testes and male infertility. Pharmacogenet and Genomics 200818 193-200. (doi:10.1097/FPC.0b013e3282f4e98c)

15 Brokken LJS, Lundberg-Giwercman Y, Rajpert De-Meyts E, Eberhard J, Ståhl O, Cohn-Cedermark G, Daugaard G, Arver S \& Giwercman A. Association of polymorphisms in genes encoding hormone receptors ESR1, ESR2 and LHCGR with the risk and clinical features of testicular germ cell cancer. Molecular and Cellular Endocrinology 2012351 279-285. (doi:10.1016/j.mce.2011.12.018)

16 Jørgensen N, Joensen UN, Jensen TK, Jensen MB, Almstrup K, Olesen IA, Juul A, Andersson AM, Carlsen E, Petersen JH et al. Human semen quality in the new millennium: a prospective crosssectional population-based study of 4867 men. BMJ Open 20122 1197-1198. (doi:10.1136/bmjopen-2012-000990)

17 Søeborg T, Frederiksen H, Fruekilde P, Johannsen TH, Juul A \& Andersson AM. Serum concentrations of DHEA, DHEAS, $17 \alpha$-hydroxyprogesterone, $\delta 4$-androstenedione and testosterone in children determined by TurboFlow-LC-MS/MS. Clinica Chimica Acta 2013419 95-101. (doi:10.1016/j.cca.2013.01.019)

18 Vermeulen A, Verdonck L \& Kaufman JM. A critical evaluation of simple methods for the estimation of free testosterone in serum. Journal of Clinical Endocrinology and Metabolism 199984 3666-3672. (doi:10.1210/jcem.84.10.6079)
19 Henriksen LS, Hagen CP, Assens M, Busch AS, Skakkebæk NE, Almstrup K \& Main KM. Genetic variations in FSH action affect sex hormone levels and breast tissue size in infant girls: a pilot study. Journal of Clinical Endocrinology and Metabolism 2016101 3191-3198. (doi:10.1210/jc.2016-1672)

20 Gudin JA, Laitman A \& Nalamachu S. Opioid related endocrinopathy. Pain Medicine 201516 S9-S15. (doi:10.1111/pme.12926)

21 Isidori AM, Caprio M, Strollo F, Moretti C, Frajese G, Isidori A \& Fabbri A. Leptin and androgens in male obesity: evidence for leptin contribution to reduced androgen levels. Journal of Clinical Endocrinology and Metabolism 199984 3673-3680. (doi:10.1210/jc.84.10.3673)

22 Roumaud P \& Martin LJ. Roles of leptin, adiponectin and resistin in the transcriptional regulation of steroidogenic genes contributing to decreased Leydig cells function in obesity. Hormone Molecular Biology and Clinical Investigation 201524 25-45. (doi:10.1515/hmbci-2015-0046)

23 Jørgensen N, Liu F, Andersson AM, Vierula M, Irvine DS, Auger J, Brazil CK, Drobnis EZ, Jensen TK, Jouannet P et al. Serum inhibin-b in fertile men is strongly correlated with low but not high sperm counts: a coordinated study of 1797 European and US men. Fertility and Sterility 201094 2128-2134. (doi:10.1016/j.fertnstert.2009.12.051)

24 Desai SS, Achrekar SK, Pathak BR, Desai SK, Mangoli VS, Mangoli RV $\&$ Mahale SD. Follicle-stimulating hormone receptor polymorphism (G-29A) is associated with altered level of receptor expression in granulosa cells. Journal of Clinical Endocrinology and Metabolism 2011 96 2805-2812. (doi:10.1210/jc.2011-1064)

25 Grigorova M, Punab M, Punab AM, Poolamets O, Vihljajev V, Žilaitiene B, Erenpreiss J, Matulevičius V \& Laan M. Reproductive physiology in young men is cumulatively affected by FSH-action modulating genetic variants: FSHR -29G/A and c.2039 A/G, FSHB -211G/T. PLoS ONE 20149 1-10. (doi:10.1371/journal.pone.0094244)

26 Casarini L, Moriondo V, Marino M, Adversi F, Capodanno F, Grisolia C, La Marca A, La Sala GB \& Simoni M. FSHR polymorphism p.N680S mediates different responses to FSH in vitro. Molecular and Cellular Endocrinology 2014393 83-91. (doi:10.1016/j.mce.2014.06.013)

27 Lindgren I, Bååth M, Uvebrant K, Dejmek A, Kjaer L, Henic E, Bungum M, Bungum L, Cilio C, Leijonhufvud I et al. Combined assessment of polymorphisms in the LHCGR and FSHR genes predict chance of pregnancy after in vitro fertilization. Human Reproduction 201631 672-683. (doi:10.1093/humrep/dev342)

28 Grigorova M, Punab M, Poolamets O, Sõber S, Vihljajev V, Žilaitienẻ B, Erenpreiss J, Matulevičius V, Tsarev I \& Laan M. Study in 1790 Baltic men: FSHR Asn680Ser polymorphism affects total testes volume. Andrology 20131 293-300. (doi:10.1111/j.2047-2927.2012.00028.x)

29 Piersma D, Verhoef-Post M, Look MP, Uitterlinden AG, Pols HAP, Berns EMJJ \& Themmen AP. Polymorphic variations in exon 10 of the luteinizing hormone receptor: functional consequences and associations with breast cancer. Molecular and Cellular Endocrinology 2007276 63-70. (doi:10.1016/j.mce.2007.06.007)

30 Mongan NP, Hughes IA \& Lim HN. Evidence that luteinising hormone receptor polymorphisms may contribute to male undermasculinisation. European Journal of Endocrinology $2002 \mathbf{1 4 7}$ 103-107. (doi:10.1530/eje.0.1470103)

31 Müller T, Gromoll J \& Simoni M. Absence of exon 10 of the human luteinizing hormone (LH) receptor impairs LH, but not human chorionic gonadotropin action. Journal of Clinical Endocrinology and Metabolism 200388 2242-2249. (doi:10.1210/jc.2002-021946)

32 Schwarzstein L, Aparicio NJ, Turner D, de Turner EA, Premoli F, Rodriguez A \& Schally AV. Pituitary and testicular response to hypothalamic LH-releasing hormone (LH-RH) in normal and oligospermic men. International Journal of Fertility and Sterility $1976 \mathbf{1 0}$ 96-102. (doi:10.1111/j.1439-0272.1978.tb01316.x)

33 Saez JM \& Forest MG. Kinetics of human chorionic gonadotropininduced steroidogenic response of the human testis. I. Plasma testosterone: implications for human chorionic gonadotropin 
stimulation test. Journal of Clinical Endocrinology and Metabolism 1979 49 278-283. (doi:10.1210/jcem-49-2-278)

34 Saal W, Glowania HJ, Hengst W \& Happ J. Pharmacodynamics and pharmacokinetics after subcutaneous and intramuscular injection of human chorionic gonadotropin. Fertility and Sterility 199156 225-229. (doi:10.1016/S0015-0282(16)54476-8)

35 Meier C, Christ-Crain M, Christoffel-Courtin C, Staub JJ \& Müller B. Serum estradiol after single dose hCG administration correlates with Leydig cell reserve in hypogonadal men: reassessment of the hCG stimulation test. Clinical Laboratory $2005 \mathbf{5 1} 509-515$.

36 Gerhard I, Lenhard HK, Eggert-Kruse W \& Runnebaum B. Hormone load tests in infertile male patients. Archives of Andrology 199127 129-147. (doi:10.3109/01485019108987664)

37 Cohen R, Bouquier D, Biot-Laporte S, Vermeulen E, Claustrat B, Cherpin MH, Cabrera P, Guidetti P, Ferry S, Bizollon CA et al. Pituitary stimulation by combined administration of four hypothalamic releasing hormones in normal men and patients. Journal of Clinical Endocrinology and Metabolism 198662 892-898. (doi:10.1210/jcem-62-5-892)

38 Sheldon WR, Debold CR, Evans WS, Decherney GS, Jackson RV, Island DP, Thorner MO \& Orth DN. Rapid sequential intravenous administration of four hypothalamic releasing hormones as a combined anterior pituitary function test in normal subjects. Journal of Clinical Endocrinology and Metabolism 198560 623-630. (doi:10.1210/jcem-60-4-623)

39 Wehrenberg WB, Baird A, Ying SY, Rivier C, Ling N \& Guillemin R. Multiple stimulation of the adenohypophysis by combinations of hypothalamic releasing factors. Endocrinology 1984114 1995-2001. (doi:10.1210/endo-114-6-1995)

40 O'Shaughnessy PJ, Fleming LM, Jackson G, Hochgeschwender U, Reed P \& Baker PJ. Adrenocorticotropic hormone directly stimulates testosterone production by the fetal and neonatal mouse testis. Endocrinology 2003144 3279-3284. (doi:10.1210/ en.2003-0277)

41 Whirledge S \& Cidlowski JA. Glucocorticoids, stress, and fertility. Minerva Endocrinologica 201035 109-125. (doi:10.1586/eem.10.1)

42 Harman SM, Tsitouras PD, Costa PT \& Blackman MR. Reproductive hormones in aging men. II. Basal pituitary gonadotropins and gonadotropin responses to luteinizing hormone-releasing hormone. Journal of Clinical Endocrinology and Metabolism 198254 547-551. (doi:10.1210/jcem-54-3-547)

Received 3 November 2016

Revised version received 5 December 2016

Accepted 11 January 2017 